Experimental behaviour of concrete filled thin walled steel tubes with tab stiffeners JOURNAL OF CONSTRUCTIONAL STEEL RESEARCH 66(7):915$92201 \mathrm{Jul} 2010$

\title{
EXPERIMENTAL BEHAVIOUR OF CONCRETE FILLED THIN WALLED STEEL TUBES WITH TAB STIFFENERS
}

\author{
Petrus C, Hamid HA, Ibrahim A, Parke G
}

\begin{abstract}
This paper presents an experimental investigation into the structural behaviour of concrete filled thin walled steel tubular stub column with tab stiffeners. The stiffening was attained by welding together four pieces of lipped angle, where two parts of the lips were notched and folded vertically in order to form the tab stiffeners. The effects of the tab stiffeners on the bond and compressive strengths were investigated experimentally on 18 and 5 specimens respectively. It was observed that the tab stiffener does enhance both the bond strength and the axial load capacity of the concrete filled thin walled steel tubular stub column tested.
\end{abstract}

Keywords: concrete filled tubes; thin walled; bond strength; stiffeners; ductility 


\section{Introduction}

Concrete filled steel tubular (CFT) columns are a structural system with excellent structural characteristics, which resulted from the confinement, provided by the steel tube, to the concrete core. However, this confinement is not very effective in a rectangular section as compared to that of a circular section. Therefore, when a rectangular section of CFT is used, a stiffening method is desirable, especially when thin walled steel section are used.

There are several types of stiffening method available for used in CFT. For instance, welding longitudinal stiffeners on the inner surfaces of the steel tube, inserting shear studs in the steel tube and in addition, by using either tie bars or restraining rods to strengthen the plastic zones of the CFTs, [1,2]. Ge and Usami, (1992) have studied experimentally the effect of longitudinal stiffeners on the behaviour of square CFT stub columns as shown in Figure 1(b). The test results demonstrated that the longitudinal stiffeners effectively delay the local buckling of the tube, increase the sectional capacity and improve the lateral confinement of the concrete core, [3]. However, the longitudinal stiffeners did not significantly influence the ductility of the stiffened CFT specimens, [4]. Welding shear studs as shown in Figure 1(c) is another well-known stiffening method. The shear studs function as shear connecters to ensure reliable stiffness of the composite cross section even in the region of elastic behaviour. This stiffening scheme primarily aims at enhancing the ultimate strength of the steel tube and improving the bond between the steel tube and concrete core interface, $[5,6]$. However, the shear studs only enhance the ductility of square CFT columns but they contribute nothing to the strength. Figure 1(d), shows another stiffening method where a set of four inclined steel bars or tie bars have been welded onto the steel sections. Figure 1(e) and 1(f) show restraining rods at regular spacing along the longitudinal axis of the steel tube used to actively strengthen the confinement of the concrete core provided by the steel tube. According to these studies, the tie bars and restraining rods did help to enhance the behaviour of square CFT columns both in terms of ultimate strength and ductility. However, the layout of the tie bars and the restraining rods complicates construction.

The available literature indicates that strength and ductility are equally important on CFT stiffening design. A CFT stiffener that poses both characteristics is still lacking, therefore more study in this area is needed. 


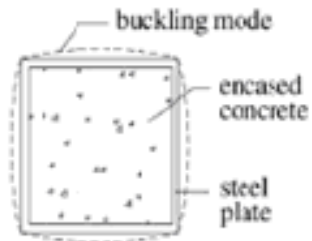

(a)

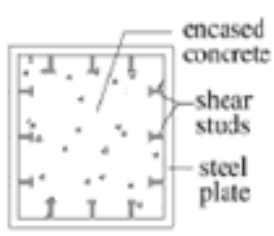

(c)

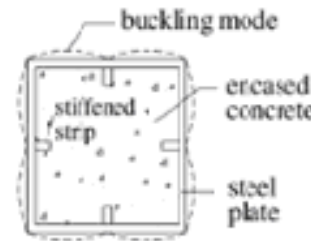

(b)

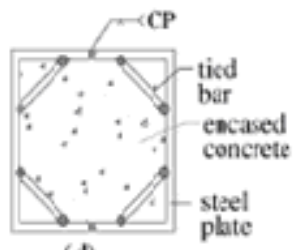

(d)

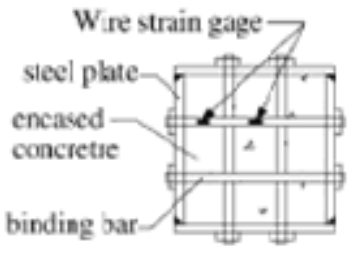

(e)



(f)

Figure 1: Cross-sections of square CFT columns with different stiffening measures. (a) without stiffeners; (b) with stiffened strips; (c) with shear studs; (d) with inclined tie bars; (e) with binding bars; and (f) with restraining rods.

This paper presents an experimental investigation into the bond strength and axial load capacity of concrete filled thin walled tubular stub columns with a novel stiffening method called tab stiffeners as shown in Figure 2. The stiffening method introduced is an improved stiffening system where both the longitudinal stiffener and tab stiffener are provided. The purposes of this stiffening method are to increase the ultimate capacity, to improve the ductility and also to overcome the shortcoming of weak concrete confinement at the centre of the sidewalls of the rectangular steel tubes. The tab stiffener is expected to function in a similar manner as a shear stud thus, expected to improve the ductility whereas, the longitudinal stiffeners are expected to increase the ultimate axial load capacity of a CFT column. This stiffening system can also reduce the welding effort when compared to the system introduced by Tao et. al. (2005), thus reducing residual stresses induced by welding.
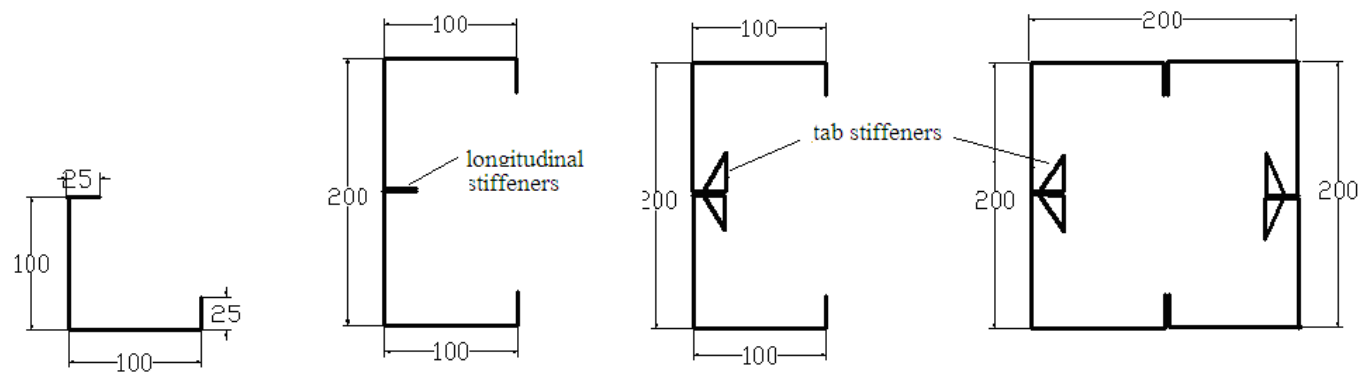

Figure 2: A new proposed stiffening method

\section{Experimental program}

Twenty square specimens with longitudinal and tab stiffeners, including fifteen specimens for push out test and five specimens for compression test were prepared. The 
push out test and compression test were conducted to determine the bond strength between the steel and concrete interface and the axial load capacity. The primary parameters studied were the tab stiffener spacing and the behaviour of different type of stiffeners.

All specimens cross section were square with an overall width (B) of $200 \mathrm{~mm}$, a tube thickness of $2 \mathrm{~mm}$ and a yield strength, $\mathrm{f}_{\mathrm{y}}$ of $309 \mathrm{MPa}$. According to the design code EC4 the slenderness of the walls must satisfy the limiting value of $\mathrm{B} / \mathrm{t}$ to avoid local buckling of the steel. The limiting value of $\mathrm{B} / \mathrm{t}$ for rectangular CFTs is

$$
B / t \leq 52 \sqrt{\frac{235}{f_{y}}}
$$

where $\mathrm{B}$ is the greater overall dimension, $\mathrm{t}$ is the thickness of the steel plate and $\mathrm{f}_{\mathrm{y}}$ is the yield strength in $\mathrm{MPa}$. According to this equation, the slenderness limit of all the specimens is 54. However, a width-to-thickness ratio (B/t) of all the specimens in this study is 100, therefore all specimens were considered to be thin walled section. A stiffening measures was taken to compensate for the local buckling effects of the thin walled tubes. The sizes of the stiffeners were determined according to the rigidity requirement for stiffeners developed by Zhong Tao (2005) as follows;

$$
I_{s, r e}=3.1 \times 10^{-4} \cdot\left(\frac{w}{t}\right)^{3.5} \frac{f_{y, t}}{280} t^{4}
$$

where, $I_{s, r e}$ is the stiffeners rigidity requirement, $\mathrm{w}$ is the width of the sub-panel plate, which can be taken approximately as, $w=\mathrm{b} / 2$, where $\mathrm{b}$ is the overall width of the tube and $f_{y, t}$ is the yield stress of tube. For a $200 \mathrm{~mm} \times 200 \mathrm{~mm}$ steel box tube, the $I_{s, r e}$ is $3914 \mathrm{~mm}^{4}$, which requires approximately $22.7 \mathrm{~mm}$ height and $4 \mathrm{~mm}$ thick stiffener. Therefore, the dimension of a stiffener was chosen as $25 \mathrm{~mm}$ height and $4 \mathrm{~mm}$ thick, which gives a stiffeners rigidity of $5208 \mathrm{~mm}^{4}$.

The details of the specimens for the push out test are listed in Table 1. The main parameters considered are on the variations of the spacing of tab stiffeners and concrete grades for the infill. The tab spacings used were $75 \mathrm{~mm}, 100 \mathrm{~mm}, 150 \mathrm{~mm}$ and $300 \mathrm{~mm}$ centre to centre. Three specimens were prepared for each value of tab spacing and three more specimens with four longitudinal stiffeners for the purpose of comparison.

\begin{tabular}{|c|c|c|c|c|c|c|}
\hline $\begin{array}{c}\text { Specimen } \\
\text { Label }\end{array}$ & $\begin{array}{c}\text { Concrete } \\
\text { Strength, } \\
\mathrm{f}_{\mathrm{cu}} \\
\left(\mathrm{N} / \mathrm{mm}^{2}\right)\end{array}$ & $\begin{array}{c}\text { Tab } \\
\text { Spacing } \\
l_{\mathrm{t}}(\mathrm{mm})\end{array}$ & $\begin{array}{l}\text { No. of } \\
\text { Tabs }\end{array}$ & $\begin{array}{l}\text { Failure Load, } \\
\quad \mathrm{N}(\mathrm{kN})\end{array}$ & $\begin{array}{c}\text { Average } \\
\text { Failure } \\
\text { Load, N } \\
(\mathrm{kN})\end{array}$ & $\begin{array}{c}\text { Bond } \\
\text { Strength } \\
(\mathrm{MPa})\end{array}$ \\
\hline $\begin{array}{l}\text { SL(1) } \\
\text { SL(2) } \\
\text { SL(3) }\end{array}$ & $\begin{array}{l}40 \\
40 \\
40\end{array}$ & - & - & $\begin{array}{l}173 \\
176 \\
175 \\
\end{array}$ & 175 & 0.4 \\
\hline
\end{tabular}

Table 1 : Details of the specimens for the push out test. 


\begin{tabular}{|l|l|c|c|c|c|c|}
\hline ST75(1) & 40 & 75 & & 260 & 263 & 0.60 \\
ST75(2) & 40 & 75 & 10 & 265 & 263 & \\
ST75(3) & 40 & 75 & & 264 & & \\
\hline ST100(1) & 40 & 100 & & 249 & 0.60 \\
ST100(2) & 40 & 100 & 8 & 284 & 262 & \\
ST100(3) & 40 & 100 & & 253 & & \\
\hline ST150(1) & 40 & 150 & & 220 & & \\
ST150(2) & 40 & 150 & 6 & 192 & 227 & \\
ST150(3) & 40 & 150 & & 268 & & \\
\hline ST300(1) & 40 & 300 & & 222 & & \\
ST300(2) & 40 & 300 & 4 & 208 & 215 & \\
ST300(3) & 40 & 300 & & $*$ & & \\
\hline
\end{tabular}

For the specimen designation, the letter $\mathrm{S}$ refer to the cross sectional shape and the following letter $\mathrm{L}$ or $\mathrm{T}$ refer to longitudinal or tab stiffeners. The following number is the tab spacing with the numeric character in bracket indicating the number of identical specimens.

Table 2: Short column specimen details.

\begin{tabular}{|c|c|c|c|c|c|}
\hline $\begin{array}{c}\text { Specimens } \\
\text { label }\end{array}$ & $\begin{array}{c}l_{\mathrm{c}} \\
(\mathrm{mm} \mathrm{c} / \mathrm{c})\end{array}$ & $\begin{array}{c}\mathrm{f}_{\mathrm{cu}} \\
\left(\mathrm{N} / \mathrm{mm}^{2}\right)\end{array}$ & $\begin{array}{c}\mathrm{f}_{\mathrm{y}} \\
(\mathrm{MPa})\end{array}$ & $\begin{array}{c}\mathrm{N}_{\mathrm{ue}} \\
(\mathrm{kN})\end{array}$ & DI \\
\hline LUC1 & - & - & 300 & 347 & 2.67 \\
TUC2 & 150 & - & 300 & 312 & 1.71 \\
LCFT1 & - & 36 & 300 & 1280 & 2.85 \\
TCFT1 & 150 & 36 & 300 & 1291 & 2.11 \\
TCFT2 & 150 & 36 & 300 & 1301 & 2.63 \\
\hline
\end{tabular}

Table 2 presents the details of the specimens used for the compression test to preliminary determine the ultimate axial load capacity of CFT column with tab stiffeners. The specimens label starting with a $\mathrm{L}$ or $\mathrm{T}$ refer to longitudinal and tab stiffeners respectively. The letter UC which follows, represent an empty steel column and CFT represent a concrete filled column. The length of each specimen is chosen to be three times the height of the square thin walled steel columns to avoid the effects of overall buckling and end conditions.

\subsection{Material Properties}

All the specimens were fabricated from mild steel sheeting with a measured thickness of $2 \mathrm{~mm}$. The yield strength and the elastic modulus of the steel sheeting were $309 \mathrm{MPa}$ and $200 \mathrm{GPa}$ respectively, which had been determined from tensile test on three coupons.

Normal strength concrete of grade 30 with a water cement ratio of 0.5 was used for the infill. The compressive strength of concrete was determined from three $150 \mathrm{~mm}$ cubes 
taken from each batch of concrete. The average concrete cube strength $\left(f_{\text {cu }}\right)$ at 28 days was $40 \mathrm{MPa}$ and $36 \mathrm{MPa}$ for push out tests and compressive tests respectively.

\subsection{Specimen Preparations}

The steel tubes with longitudinal and tab stiffeners used for this study are manufactured from mild steel sheeting with a measured thickness of $2 \mathrm{~mm}$. The steel sheeting was cut and pressed to form a lipped equal angle of $100 \mathrm{~mm} \times 100 \mathrm{~mm}$ width $\mathrm{x}$ $600 \mathrm{~mm}$ long and $25 \mathrm{~mm}$ lip height. Two pieces of the lipped angles were welded throughout its length to form a lipped channel with longitudinal stiffeners. The tab stiffeners were then made by notching the lip in the middle slanting $50 \mathrm{~mm}$ downward with about $5 \mathrm{~mm}$ tolerance at a required spacing and folding them horizontally in the right, and left directions subsequently. Finally, a square tube with two longitudinal stiffeners and two tab stiffeners was produced by seam welding together two pieces of lipped channel with tab stiffeners. Steel tubes with four longitudinal stiffeners was also provided by seam welding four pieces of lipped angle section as a comparison purpose. The details of the specimens are shown in Figure 3(a) and (b).



(a)

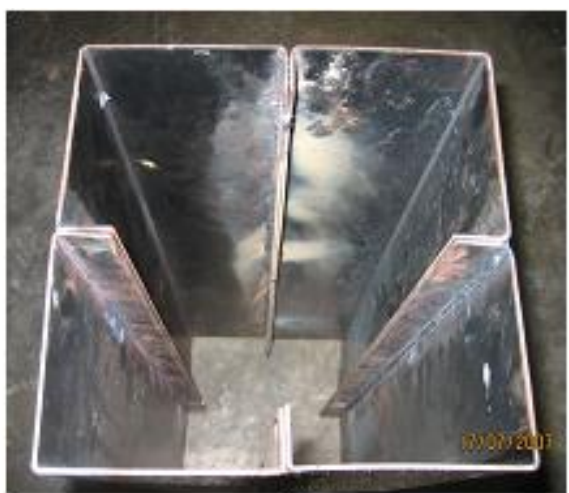

(b)

Figure 3: (a) the steel box column with two tab stiffeners and two longitudinal stiffeners and (b) the steel box column with four longitudinal stiffeners as control specimen.

Fifteen square hollow steel section $200 \mathrm{~mm}$ x $200 \mathrm{~mm}$ wide and $2 \mathrm{~mm}$ thick specimens with stiffeners were prepared for the push out test. Each specimen is $600 \mathrm{~mm}$ long, and the length of the steel-concrete interface has been maintained at approximately $550 \mathrm{~mm}$. Three specimens having four longitudinal stiffeners were prepared to act as control specimens. Four different values of tab spacing i.e $75 \mathrm{~mm}, 100 \mathrm{~mm}, 150 \mathrm{~mm}$ and $300 \mathrm{~mm}$ were considered. For each value of the tab spacing, three specimens were filled with concrete. The bottom of the specimen was stiffened by welding four pieces of $200 \mathrm{~mm}$ width $\times 100 \mathrm{~mm}$ height $\times 3 \mathrm{~mm}$ thick plate to avoid any local buckling at the bottom part of the steel box during testing. A tiny $\mathrm{V}$ notch of $7 \mathrm{~mm}$ was provided at the bottom of the tubes to release any trap air during testing. 
During concrete casting, the specimens were placed in an upside down position and filled with concrete to a length of $550 \mathrm{~mm}$ leaving a $50 \mathrm{~mm}$ gap at the top of the specimen. The $50 \mathrm{~mm}$ air gap was provided to allow the concrete core to travel during testing.

Five specimens, including three specimens with tab stiffeners and two specimens with longitudinal stiffeners were prepared for the compression test. A $2 \mathrm{~mm}$ thick square flat plate of $250 \mathrm{~mm}$ width was welded to the base of the steel tubes in order to support the wet concrete during casting.

The concrete was placed in layers for all specimens and was vibrated by a poker vibrator. After the concrete had been cast into the steel hollow section, the specimens were left with the top open to the air until testing. Prior to testing, the top and bottom surfaces of the empty columns were cut and ground smooth to ensure that the load was applied evenly across the cross section.

\subsection{Test set-up and instrumentation}

A $2000 \mathrm{kN}$ capacity universal testing machine was used for both the push out and compressive tests. The test set-up for the push out test is shown in Figure 4. A 50mm thick steel loading pad with sides about $10 \mathrm{~mm}$ smaller than the internal dimension of the specimens being tested was placed at the top end between the specimen and the loading surface of the testing machine. The steel loading pad is provided with four grooves of $30 \mathrm{~mm} \times 8 \mathrm{~mm}$ at its mid sidewall to accommodate the steel tube's stiffeners. Four 50mm travel electrical transducers were placed at the middle of each edge of the steel tube to measure the movement of the concrete core with respect to the steel tube. The push out test was performed at a displacement rate of $0.01 \mathrm{~mm}$ per second. The movement of the concrete core is taken to be the average of the four transducers readings. The load was applied through the steel block to the concrete, which could then move vertically relative to the steel section when the bond resistance of the concrete steel interface had exceeded.


Figure 4: Push Out Test set up and Instrumentation 
For the compression test, a $2000 \mathrm{kN}$ capacity universal testing machine was used. A computerized IMP data acquisition system was used for data logging. Four displacement transducers were used to measure the axial shortening during the test. A load increment of less than one tenth of the estimated load capacity was used. Each load increment was maintained for about 2 minutes.
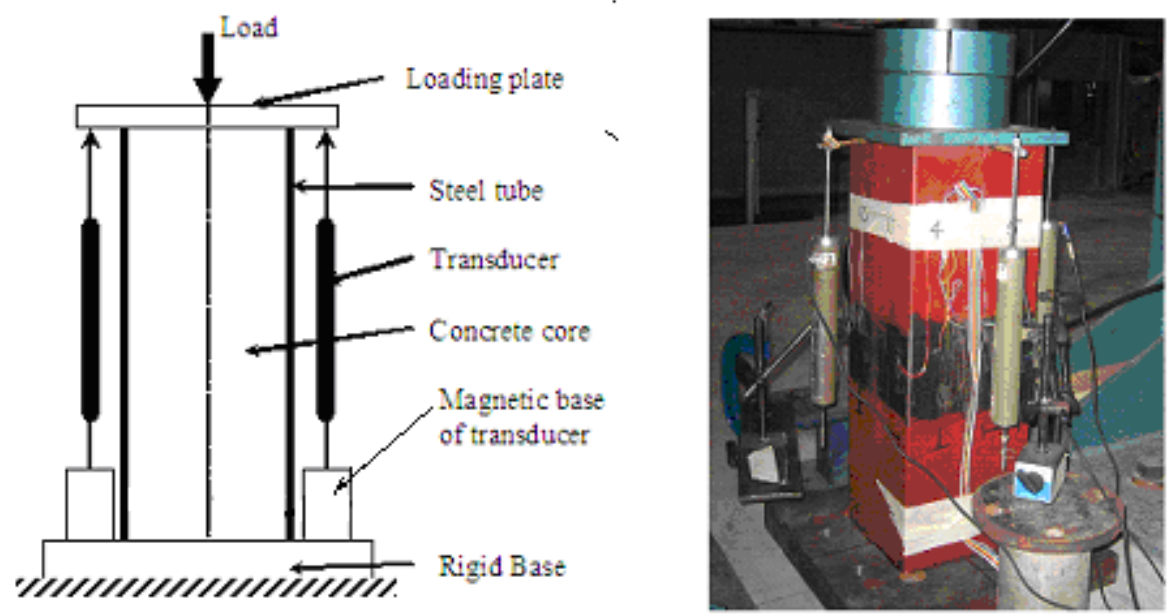

Figure 5: Compression test set up and instrumentations

\section{Experimental results and discussion}

\subsection{Bond strength}

The slip of the concrete core was recorded by the use of the displacement transducers. A summary of the test results and bond strengths of the specimens were determined and presented in Table 2. The load carrying capacity of the tab stiffener is determined by subtracting the average failure load of the specimen from the control specimen. This would give an average load carrying capacity of $88 \mathrm{kN}, 87 \mathrm{kN}, 52 \mathrm{kN}$ and $40 \mathrm{kN}$ for $10,8,6$ and 4 numbers of tab stiffeners respectively. Therefore, each tab stiffener has a carrying load capacity in average of about $10 \mathrm{kN}$. If this value is compared to the carrying capacity of the M12 bolt studied by Shakir-Khalil, (1991), the tab stiffener attained only about $13 \%$ of the carrying capacity of the M12 bolts. This indicates that tab stiffeners do contribute to the enhancement of bond resistance at the steel concrete interface compared to un-stiffened CFT $[7,8]$.

The bond strength at the interface between the steel and the concrete is calculated from the equation:

$$
\mathbf{F}_{\mathbf{b}}=\mathbf{N} / \mathbf{A}
$$

where, $\mathrm{F}_{\mathrm{b}}$ is the bond strength at the steel concrete interface, $\mathrm{N}$ is the failure load applied to the specimen and $\mathrm{A}$ is the contact area at the steel concrete interface. 
The average bond strength of the control specimens give an average bond strength of $0.4 \mathrm{MPa}$ which is equivalent to the design shear strength value assumed in EC4 for concrete filled rectangular hollow sections. The rest of the specimens show significant improvement in the bond strength, which is as high as 50\%.

The force-displacement behaviour of some of the test specimens are presented in Figure 6 . From the force-displacement relationships, it is clearly shown that the bond resistance of the specimen with tab stiffeners is greater than that obtained from the control specimen. The force-displacement relationship of the control specimen shows that little slip had taken place in the elastic range, and also that the concrete core travels steadily after the initial bond failure. In the case of the specimens with tab stiffeners, it seems that in the plastic region the concrete-steel bond is transferred to the tab stiffeners. All the specimens reached the peak push-out load at an early stage of loading and then debonding occurred with a sudden loss of bond. However, the concrete core did not really travel freely after the de-bonding. After de-bonding and the decrease in bond stress, the push-out load increases again due to the enhanced interlocking of steel and concrete at the tab stiffeners. At relatively large slip values, the wall of the steel section at the tab stiffeners location buckles, thus increasing the resistance to further slip. The higher resistance to further slip is also caused by a larger shear area to resist the applied force, which resisted the applied force in tension. This indicates that the tab stiffeners do not only improve the bond strength but also delay the concrete core slip after the steelconcrete bond has failed.

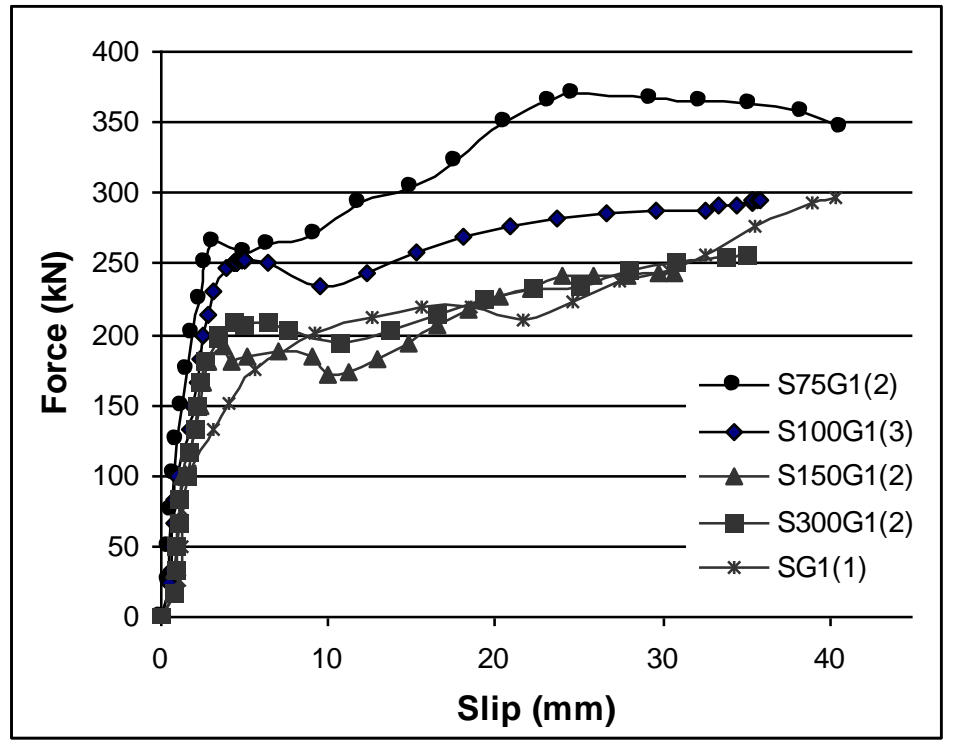

Figure 6: Force slip curves for different tab spacing

The influence of the tab spacing to the bond strength is shown in Figure 7. The bond strength is improved as the tab stiffener spacing is reduced. This is due to the increasing number of tab stiffeners interacting with the concrete as the tab spacing is reduced. Figure 7 shows that the bond strength is highest with a tab stiffener spacing of $75 \mathrm{~mm}$ centre to centre. However, there is no significant difference in bond strength with the tab 
stiffener spacing of $100 \mathrm{~mm}$ and $75 \mathrm{~mm}$ centre to centre. Therefore, a tab stiffener spacing of $100 \mathrm{~mm}$ centre to centre should be used for future work.



Figure 7: Influence of the tab spacing on the bond strength

\subsection{Compressive strength}

Figure 8, shows the typical failure apperance of the specimens after the compressive test. The buckling modes of the panel plate after collapse of these speciemens are also shown in Figure 9. For the empty steel columns, shown in Figure 9(a), a pattern of inward and outward local buckles developed generally restrained by the stiffeners unless the stiffeners themselves buckle. For all the CFT specimens the steel panels buckled outward as shown in Figure 9(b). This shows that the stiffeners improve the confinement of the sidewalls of the square CFT, thus increasing the effective width of the cross section.

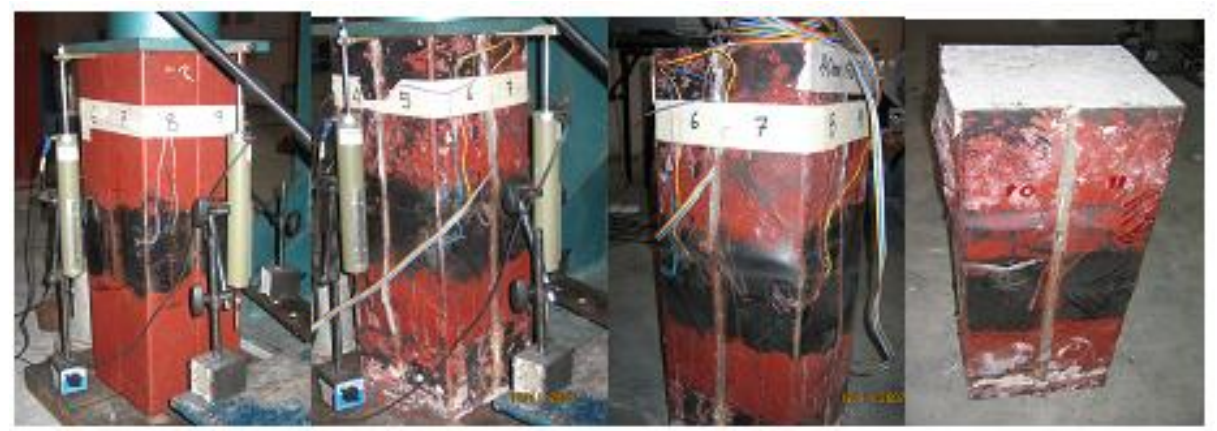

Figure 8: Typical failure appeareance of test specimens

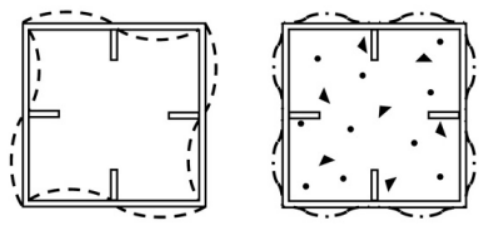


Figure 9: Local buckling modes of test specimens: (a) stiffened steel column; (b) stiffened CFT column.

Local buckling occured initially at the upper end of the specimen, then the steel panels buckled at different locations, including the central part of the speciemens. It started with the apperance of several fine lines at $45^{\circ}$ to the principal axis of the tube at about 1000 $\mathrm{kN}$, extending steadidly as the force was increased. Finally, buckling deformations developed swiftly at one of these loactions, normally near the mid height of the column. There is no significant differences in the buckling modes of all the steel panels at the tab stiffeners and the longitudinal stiffeners faces.

The maximum loads $\left(\mathrm{N}_{\mathrm{ue}}\right)$ obtained from the compressive test are summarized in Table 4 . Figure 10 shows the force displacement curves from the compression test results. The ultimate strength of the stiffened CFT column is estimated initially using the sum of the section capacities of the concrete, the steel tube and the steel stiffeners, i.e.

$$
\mathrm{N}_{0}=f_{c} A_{c}+f_{y, t} A_{s, t}+f_{y, s} A_{s, s}
$$

Where $A_{c, t,} A_{s, t,} A_{s, s}$ are the areas of the concrete, the steel tube and steel stiffeners, respectively; $f_{y, t}$ and $f_{y, s}$ are the yield strengths of the steel tube and the steel steel stiffeners respecyively; $f_{c}$ is the characteristic concrete strength, calculated as $f_{c=} O .4 f_{c u}$ ${ }^{7 / 6}[9]$. For the empty steel colum, Eq. (3) is also used to calculate $N_{0}$ by taking the cross sectional area of concrete as zero. It is assumed that there will be no axial force resistance from the tab stiffener, therefore for the tab stiffener $A_{s, s}$ is also taken as zero.

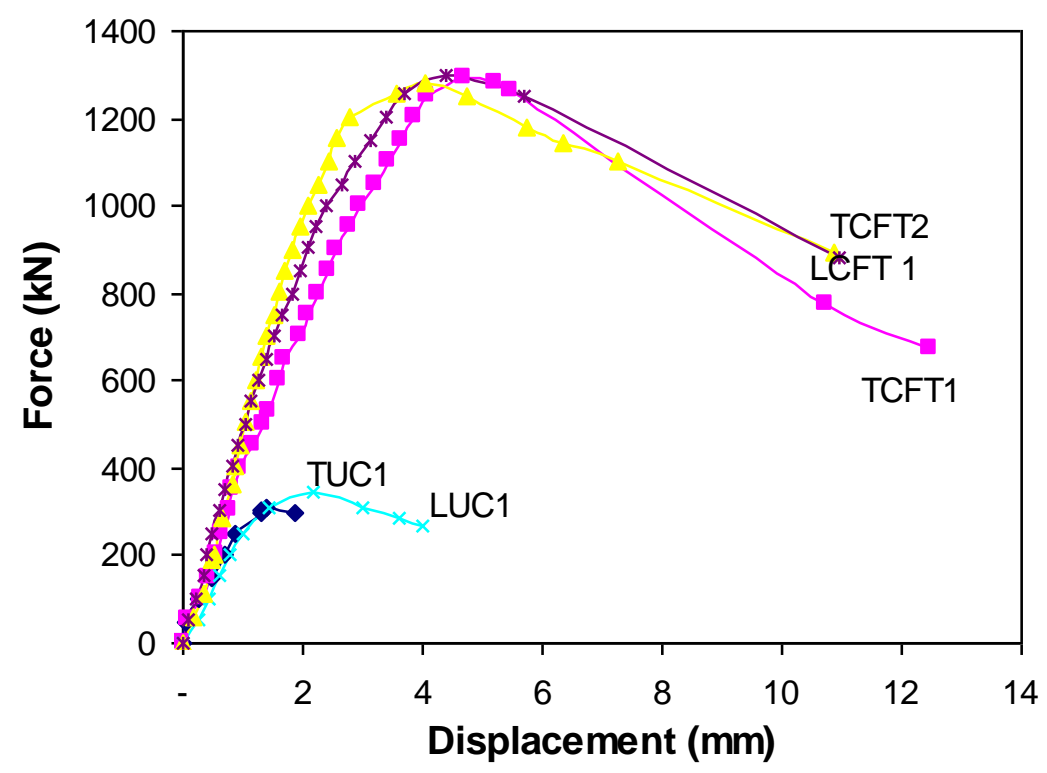

Figure 10: Load versus displacement curves. 
The ultimate axial load capacity values obtained in the experimental investigation were slightly higher than the predicted values for all the CFT specimens. However, the ultimate axial load capacity of the empty tubes were overestimated by $44 \%$. For the empty steel tubes, the maximum load capacity of the empty steel tubes with longitudinal stiffeners, LUC1 is higher than the empty steel tube with tab stiffeners, TUC1. This result is expected because when the stiffeners has been cut and folded horizontally in the right and left directions, the stiffener's strength in the longitudinal direction decreases. Therefore, the lip is no longer beneficial to the force resistance in the axial direction.

The ultimate strength of the stiffened CFT columns was greatly increased as a direct result of the concrete infilling. It is noted that the compressive strength of the specimens with tab stiffeners, TCFT1 and TCFT2 are slightly higher compared to the specimen with longitudinal stiffeners, LCFT1. The result shows that the tab stiffener does contribute to the improvement of the ultimate axial load capacity of CFT. This is due to the improvement of the bond strength of the tab stiffeners that compensates the loss of its axial stiffness.

\subsubsection{Load carrying capacity prediction}

The are several design codes used for predicting the capacity of CFTs, such as ACI, BS5400 and EC4. In this paper the design equation recommended in the codes mentioned above are applied to predict the sections axial load capacity of CFT with tab stiffeners. These equations are used with some modifications to take into account the contribution of the stiffeners. The predicted strength using ACI[9], BS5400 [10] and EC4 [11] compared with the current experimental values of the test specimens with tab stiffeners are presented in Table 3.

Table 3: Comparison between predicted ultimate strengths and test results

\begin{tabular}{|c|c|c|c|c|c|c|c|c|}
\hline $\begin{array}{c}\text { Specimen } \\
\text { label }\end{array}$ & $\begin{array}{c}l_{\mathrm{c}} \\
(\mathrm{mm} \mathrm{c} / \mathrm{c})\end{array}$ & $\begin{array}{c}N_{u e} \\
(k N)\end{array}$ & $\begin{array}{c}N_{A C I} \\
(k N)\end{array}$ & $N_{A C I} / N_{u e}$ & $\begin{array}{c}N_{B S 5400} \\
(k N)\end{array}$ & $N_{B S 5400} / N_{u e}$ & $\begin{array}{c}N_{E C 4} \\
(k N)\end{array}$ & $N_{E C 4} / N_{u e}$ \\
\hline LUC1 & - & 347 & 590 & 1.7 & 590 & 1.7 & 590 & 1.7 \\
TUC2 & 150 & 312 & 530 & 1.69 & 530 & 1.69 & 530 & 1.69 \\
LCFT1 & - & 1280 & 1570 & 1.23 & 1523 & 1.19 & 1743 & 1.36 \\
TCFT1 & 150 & 1291 & 1510 & 1.17 & 1464 & 1.13 & 1682 & 1.30 \\
TCFT2 & 150 & 1301 & 1510 & 1.16 & 1464 & 1.13 & 1682 & 1.29 \\
\hline
\end{tabular}

The nominal strength of CFT short columns according to ACI, BS5400 and EC4 is given in Eq. (5), (6), and (7) as follows,

$$
\begin{aligned}
& N_{A C I}=A_{s} f_{y}+0.85 A_{c} f_{c} \\
& N_{B S 5400}=A_{s} f_{y}+0.675 A_{c} f_{c u}
\end{aligned}
$$


$\mathbf{N}_{\mathrm{EC} 4}=\mathbf{A}_{\mathrm{s}} \mathbf{f}_{\mathbf{y}}+\mathbf{A}_{\mathbf{c}} \mathbf{f}_{\mathbf{c}}$

where $A_{s}$ and $A_{c}$ are the area of steel and concrete respectively; $f^{\prime}{ }_{c}$ and $f_{c u}$ are the characteristic compressive cylinder and cube strength of the concrete respectively, while $f_{y}$ is the yield strength of the steel tube. The area of steel $A_{s}$ in this paper replaced by $A_{s, t}$ $+\mathrm{A}_{\mathrm{s}, \mathrm{s}}$ to take the contribution of the stiffeners into consideration.

As can be seen in Table 3, Eq. (5), (6), and (7) overestimates the strength of the specimens with longitudinal stiffeners by $23 \%, 19 \%$ and $36 \%$ respectively and about $16 \%, 13 \%$ and $29 \%$ for the specimens with tab stiffeners. The reason for all of the specimens showing a lower strength could be explain by inadequate spacing of the tab stiffeners. For the compression test, the spacing of the tab stiffeners is $150 \mathrm{~mm}$ centre to centre. A higher strength should be achieved if the spacing is decrease as the bond strength between the steel concrete interface is increased with decreasing spacing of tab stiffeners. Another reason could be due to residual stresses and the degradation of the steel material as a result of excessive heat during the welding process. Because the tubes are thin walled steel section, extra caution is needed during the fabrication process.

\subsubsection{Effect of tab stiffeners on ductility}

In order to quantify the effect of tab stiffeners on section ductility, a ductility index (DI), which has been used by Zhong Tao, [12] is used herein:

$$
D I=\frac{u_{85 \%}}{u_{y}}
$$

where $\mathrm{u}_{85 \%}$ is the mid-height deflection when the load falls to $85 \%$ of the ultimate load, $\mathrm{u}_{\mathrm{y}}$ is equal to $\mathrm{u}_{75 \%} / 0.75$, and $\mathrm{u}_{75 \%}$ is the mid-height deflection when the load attains $75 \%$ of the ultimate load in the pre-peak stage. The values of $\mathrm{u}_{85 \%}$ and $\mathrm{u}_{75 \%}$ can be determined from the axial load versus axial shortening response curves shown in Figure 10. The calculated ductility indexes are shown in table 2. Figure 11 shows the effect of tab stiffeners on the ductility. It seems that specimens with longitudinal stiffeners are more effective in increasing the member ductility. The DI of the specimens with tab stiffeners were lower than the specimen with longitudinal stiffeners, about $7.7 \%$ for TCFT2 and $26 \%$ for TCF1 respectively. This is due to the slight increase in ultimate axial strength of

the specimens with tab stiffeners, thus inducing a decrease in the value of $u_{85 \%}$. The benefits of the tab stiffeners to ductility might be counteracted by residual stresses due to welding and also the insufficient tab stiffeners spacing used in the specimens. 




Figure 11: Effect of tab stiffeners on the ductility

\section{Conclusions}

The bond strength of square CFT with the new proposed stiffening system incorporating, longitudinal and tab stiffeners is under investigation. Two main parameters being considered were the tab stiffener spacing and different types of stiffeners. From the push out test and the axial compression test results obtained, the following conclusions can be drawn.

i. The new proposed stiffening system improves the bond strength at the steel and concrete interface. The bond strength improves as the tab spacing become smaller. However, there is no significant difference in the bond strength with tab stiffeners spacing of $100 \mathrm{~mm}$ and $75 \mathrm{~mm}$ centre to centre. Therefore, a tab stiffener spacing of $100 \mathrm{~mm}$ centre to centre is recommended.

ii. The tab stiffeners do not only improve the bond strength but also delay the concrete core slip after the steel-concrete bond has failed. This is due to an enhanced interlocking between the concrete core and steel tube occurring at the location of tab stiffener.

iii. It is also observed that the concrete filled thin walled square steel tubes with the proposed stiffening scheme increase the ultimate axial load capacity slightly when compared to the specimen with only longitudinal stiffeners.

iv. However, the experimental ultimate axial capacities of all the specimens are lower when compared with the predicted values according to the design code in ACI, BS5400 and EC4.

v. The ductility of the CFT specimens has been evaluated by calculating the ductility index. It was found that there is no significant difference in the ductility of CFT with tab stiffeners when compared to CFT with longitudinal stiffeners. 
Generally, the proposed stiffening method can improve the bond strength and the ultimate strength capacity of concrete filled thin walled tubes provided the stiffeners are adequately design. Since the proposed stiffening method for concrete filled thin walled steel tubes shows encouraging behaviour in terms of improving the bonding strength, ultimate axial capacity and ductility, more intensive research work will be conducted in the future.

\section{Acknowledgements}

The authors would like to acknowledge the contribution of VPN Engineering Sdn Bhd in fabricating and supplying the steel materials. Thanks to all the technicians at concrete and heavy structures laboratories at UiTM for their dedication and cooperation while carrying the experimental work.

\section{References}

1. Cai, J. and Z.-Q. He, Axial load behavior of square CFT stub column with binding bars. Journal of Constructional Steel Research, 2006. 62(5): p. 472-483.

2. Hsu, H.L. and H.L. Yu, Seismic performance of concrete-filled tubes with restrained plastic hinge zones. Journal of Constructional Steel Research, 2003. 59(5): p. 587-608.

3. Tao, Z., L.-H. Han, and Z.-B. Wang, Experimental behaviour of stiffened concrete-filled thin-walled hollow steel structural (HSS) stub columns. Journal of Constructional Steel Research, 2005. 61(7): p. 962-983.

4. Zhang, Y., C. Xu, and X. Lu, Experimental study of hysteretic behaviour for concrete-filled square thin-walled steel tubular columns. Journal of Constructional Steel Research, 2007. 63(3): p. 317-325.

5. J. Punchin, N. Krstulovic-Opara, and B. Brezac, High Strength Lightweight Aggregate Fiber-Reinforced Concrete (HS-LWA FRC) Filled Steel Tube Columns for Increased Seismic Resistance. American Concrete Institute, 2003: p. 33-48.

6. Shakir-Khalil, H. Bond strength in concrete-filled steel hollow sections. in International Conference on Steel \& Aluminium Structures 1991. Singapore: Elsevier Applied Science.

7. Hunaiti, Y.M., Bond strength in battened composite columns. Journal of Structural Engineering, 1991. 117: p. 699-714. 
8. Huniati, Y.M., Composite action of foamed and lightweight aggregate concrete. Journal of Materials in Civil Engineering, 1996. 8: p. 111-113.

9. ACI Committee 318, Building code requirements for reinforced concrete (ACI 318-99) and commentary (ACI 318R-99). 1999, American Concrete Institute: Detroit.

10. BS5400, Steel, concrete and composite bridges. Part 5, Code of practice for the design of composite bridges. 2005: London, UK.

11. Eurocode 4, ed. Design of composite steel and concrete structures - Part 1-1: General rules and rules for buildings. ed. B. Standard. 2004, BSI.

12. Tao, Z., L.-H. Han, and D.-Y. Wang, Experimental behaviour of concrete-filled stiffened thin-walled steel tubular columns. Thin-Walled Structures, 2007. 45(5): p. 517-527. 